Revista de Derecho

de la Pontificia Universidad Católica de Valparaíso

XXXIV (Valparaíso, Chile, $1^{\text {er }}$ Semestre de 2010)

[pp. $281-304]$

\title{
La Cooperación de los Estados con la Corte Penal InTernacional a La LUZ DEL PRINCIPIO DE COMPLEMENTARIEDAD*
}

["States' Cooperation with the International Criminal Court in the Light of the Principle of Complementarity"]

\section{Claudia Cárdenas Aravena**}

\section{RESUMEN}

Se examina el régimen de cooperación de los Estados con la Corte Penal Internacional -tanto para los Estados Partes como para los que no lo sonseñalando las principales obligaciones de los Estados, según los casos, y las consecuencias jurídicas en caso de su incumplimiento. Se observa que, en último término, para el buen funcionamiento de la jurisdicción internacional no es crucial la posibilidad jurídica de contar con la amenaza de gravosas sanciones.

Palabras Clave: Corte Penal Internacional - Cooperación internacional - Complementariedad internacional Obligaciones estatales - Consecuencias del incumplimiento.

\section{AbSTRACT}

The cooperation regime of the States with the International Criminal Court is examined, both for the States Parties and for those which are not, pointing out the main obligations of the States, according to each case, and the legal consequences if they are not complied with. It is possible to see that, in short, for the good functioning of the international jurisdiction, the possibility of having the threat of expensive sanctions is not important.

KeYwords: International Criminal Court - International Complementarity - State obligations - Consequences of non-compliance.

* Este trabajo cuenta con el patrocinio de FondECYT (proyecto No 1080060).

** Magíster y Doctora en Derecho por la Universidad Humboldt de Berlin. Dirección Postal: Darío Urzúa 1650, depto. 503, Providencia, Santiago. Dirección electrónica: cardenascl@yahoo.de 


\section{IMPORTANCIA DE LA COOPERACIÓN PARA EL QUEHACER DE LA JUSTICIA}

PENAL INTERNACIONAL BAJO EL RÉGIMEN DE LA COMPLEMENTARIEDAD

La Corte Penal Internacional fue establecida por el Estatuto de Roma de la Corte Penal Internacional ${ }^{1}$. Dentro de su estructura cuenta con jueces, con un Ministerio Público y una Secretaría, que se ocupa de todo el andamiaje administrativo y de servicios necesario, incluyendo la Unidad de Víctimas y Testigos y la Defensa. En cambio, la Corte no tiene policía u órganos que velen por la ejecución de sus resoluciones. En el sistema previsto en el Estatuto de Roma esa parte de la labor está encargada a los Estados, que crearon la Corte y deben tener claro que esta sólo puede funcionar con su ayuda ${ }^{2}$.

A estas alturas ya es familiar la imagen del sistema de justicia internacional que subyace al establecimiento de la Corte Penal Internacional como

${ }^{1}$ Estatuto de Roma de la Corte Penal Internacional (en la versión corregida por los procesos verbales de 10 de noviembre de 1998, de 12 de julio de 1999, de 30 de noviembre de 1999 , de 8 de mayo de 2000 , de 17 de enero de 2001 y de 16 de enero de 2002), A/CONF.183/10, 17 de julio de 1998.

${ }^{2} \mathrm{El}$ hecho de que la cooperación es esencial para el quehacer de la Corte ha sido reconocido reiteradamente. Véanse: Arcos VARGAS, Marycruz, La imprescindible cooperación de los Estados con la Corte Penal Internacional, en Carrillo Salcedo, Juan Antonio (coordinador), La Criminalización de la Barbarie: La Corte Penal Internacional (Madrid, Consejo General del Poder Judicial, 2000), pp. 435 ss.; HerenCia Carrasco, Salvador (coordinador), La Corte Internacional y los Paises Andinos, tercera edición (Lima, Comisión Andina de Juristas, 2007), pp. 55 ss.; Lirola Delgado, Isabel - Martín Martínez, Magdalena, La Corte Penal Internacional, justicia versus impunidad (Barcelona, Ariel, 2001), pp. 255 ss.; MeISSNER, Jörg, Die Zusammenarbeit mit dem Internationalen Strafgerichtshof nach dem römischen Statut (Munich, Beck, 2003), pp. 5 ss.; Oostervald, Valerie - Perry, Mike - Mcmanus, John, The Cooperation of States with the International Criminal Court, en Fordhan International Law Journal, 25 (marzo 2001), p. 389; RASTAN, Rod, Testing Co-operation: The international Criminal Court and National Authorities, en Leiden Journal of International Law, 21 (2008), pp. 431, 454 y 456; UBÉDA, Muriel, L’Obligation de Coopérer avec les Jurisdictions Internationales, en Ascencio, Hervé - Decaux, Emmanuel - Pellet, Alain (directores), Droit International Pénal (París, Pedone, 2000), pp. 951 ss.; SWART, Bert, General Problems, en CASSESE, Antonio - GAETA, Paola - Jones, John, The Rome Statute of ten International Criminal Court: A Commentary (Oxford, Oxford University Press, 2002), II, p. 1589; el Informe de la Mesa sobre Cooperación, Asamblea de Estados Partes, sexto período de sesiones, Nueva York, 30 de noviembre a 14 de diciembre de 2007, ICC-ASP/6/21, parágr. 1. Incluso la importancia de la cooperación de terceros Estados ha sido puesta de relieve por Palmisano, Giuseppe, Cooperation by non-States Parties, en LATTANZI, Flavia, The International Criminal Court, Comments on the Draft Statute (Nápoles, Editoriale Scientifica, 1998), pp. 339 ss. 
un sistema de dos pilares ${ }^{3}$. Por una parte, órganos de la Corte se encargan se perseguir y juzgar los casos más graves de crímenes de genocidio, crímenes de guerra y de lesa humanidad que no estén siendo o hayan sido adecuadamente investigados o perseguidos por parte de los Estados; y por otra, los Estados se encargan de ejecutar lo necesario para posibilitar las investigaciones y hacer cumplir lo resuelto por el tribunal. Si alguno de los pilares falla, la estructura en su conjunto falla también.

Existe cierto consenso en que no parece pertinente clasificar las relaciones de cooperación entre la Corte Penal Internacional y los Estados en las categorías de cooperación horizontal (la que se da entre Estados) o cooperación vertical (la que existe entre los Estados y los Tribunales Penales Internacionales $a d h o c)^{4}$. Conforme al principio de complementariedad, el sistema de cooperación de los Estados con la Corte Penal Internacional tiene elementos de ambos modelos ${ }^{5}$, pues si bien la Corte Penal Internacional es un tribunal internacional, y los Estados Partes del tratado que la establece están obligados a cooperar con ella en la investigación y enjuiciamiento de las situaciones y casos de que conozca, ella no tiene órganos que velen por el imperio de sus decisiones con facultades coercitivas para los Estados.

\section{RELACIÓN DEL TEMA CON EL PRINCIPIO DE COMPLEMENTARIEDAD}

Conforme con el principio de complementariedad, el sistema preexistente de aplicación indirecta del derecho penal internacional se mantiene y se incentiva. Los Estados conservan intactas sus competencias para la investigación y persecución de crímenes internacionales, en tanto la Corte Penal Internacional está jurídicamente facultada para actuar sólo en casos de excepción, cuando un asunto determinado y de gravedad suficiente no ha sido abordado por las autoridades estatales o éstas no han actuado de

${ }^{3}$ Véase: "Address" by Philippe Kirsch, President of the International Criminal Court, to the United Nations General Assembly, 1 de noviembre de 2007, p. 4. Véase, además: Asamblea de Estados Partes, "Informe de la Mesa sobre Cooperación", ICC-ASP/6/21, de 19 de octubre de 2007, párrafo 39; RASTAN, Rod, The Responsibility to Enforce - Connecting Justice with Unity, en STAHN, Carsten - SLuITER, Goeran (editores), The Emerging Practice of the International Criminal Court (Leiden, Brill, 2009), pp.164 ss. RASTAN, Rod, cit. (n. 2), p. 431.

${ }^{4}$ Si bien Kress, Claus - Prost, Kimberly - Wilkizki, Peter, Part 9, en Triffterer, Otto (editor) Commentary on the Rome Statute of the International Criminal Court Observers' Notes, Article by Article (2a edición, Munich, Beck, 2008), p. 1507 ss., lo califican de "(weak) vertical cooperation regime".

${ }^{5}$ Véase: Quesada Alcalá, Carmen, La Corte Penal Internacional y la soberanía estatal (Valencia, Tirant lo Blanch, 2005), pp. 399 ss. 
acuerdo con los estándares mínimos establecidos en la regulación del Estatuto $^{6}$. En estos casos, la Corte actúa en cooperación con los Estados ${ }^{7}$.

Como la Corte actúa sobre la base del sistema preexistente (complementa y no reemplaza), forma también parte de la lógica del sistema el hecho de que para poder actuar necesita (en el sentido más estricto de la palabra) de la cooperación de los Estados y otros sujetos ${ }^{8}$.

Ya en el Comité Ad Hoc para el Establecimiento de una Corte Penal Internacional (1995) quedó de manifiesto la estrecha relación entre el principio de complementariedad y la cooperación de los Estados con la Corte, que no es más que una de sus manifestaciones. Así, el informe del Comité Ad Hoc contiene un acápite "E" denominado "Relationship between States Parties, non-States Parties and the Internacional Criminal Court”, que se regula lo que hoy se denomina el principio de complementariadad, y que se refiere justamente a la cooperación'.

Que el sistema esté planteado de esta forma también obedece a una consideración práctica, ya que no sería viable el apoyo internacional que concita y debe concitar la Corte si se tratara de una institución con policía propia, que pudiese actuar sin consultas con el Estado territorial.

Entonces, una de las manifestaciones del carácter complementario del ejercicio de la jurisdicción de la Corte consiste en la necesidad que ésta tiene de contar con la cooperación de los Estados y otras organizaciones para investigar debidamente las comunicaciones y remisiones que recibe y reunir las pruebas para probar los cargos en juicio ${ }^{10}$. Como queda dicho,

${ }^{6}$ Cárdenas Aravena, Claudia, La Corte Penal Internacional y su relación con las jurisdicciones nacionales: El principio de complementariedad, en Revista de Magister y Doctorado en Derecho, Universidad de Chile, 1 (2007), p. 123-138. En particular sobre el examen de admisibilidad, cfr. Cárdenas Aravena, Claudia, Die Zulässigkeitsprüfung vor dem Internationales Strafgerichtshof (Berlín, Berliner Wissenschaftsverlag, 2005).

${ }^{7}$ De hecho, para Bassiouni, M. Cherif, The Legislative History of the International Criminal Court: Introduction, Analysis and Integrated Text, tomo I (Ardsley, Transnational Publishers, 2005), p. 178, es en materia de cooperación donde queda de manifiesto que la Corte Penal Internacional es una institución internacional, y no supranacional.

${ }^{8}$ Con respecto de la necesidad de cooperación estatal para el funcionamiento de la Corte, véase: Cid MuÑoz, María Isabel, La Corte Penal Internacional, un largo camino (Madrid, Dykinson, 2008), pp. 85 ss.

${ }^{9}$ BAssiouni, M. Cherif, cit. (n. 7), II, p. 628. En un sentido análogo: CrYer, Robert y otros An Introduction to International Criminal Law and Procedure (Cambridge, Cambridge University Press, 2007), p. 412.

${ }^{10}$ Así lo reconoce, por ejemplo: RegGio, Andrea, Cooperation with the International Criminal Court and National Legal Sytems: An Overview of the Implementing legislations Enacted so Far, en The Global Community. Yearbook of International Law 
la Corte carece de policía propia, cuenta sólo con pequeños grupos de investigadores abocados a cada situación; y si bien en ciertos casos les está permitido actuar directamente sobre el territorio de un Estado -esto sucede previas consultas con el Estado territorial y siempre que la actuación no requiera de medidas coercitivas, p. ej., la de tomar declaración voluntaria-, por regla generalísima ${ }^{11}$, las medidas coercitivas sólo pueden ejecutarse por las autoridades estatales.

En el artículo 57 párrafo 3 letra d) del Estatuto de la Corte Penal Internacional se prevé una salida para casos extremos. Se puede "[a] utorizar al Fiscal a adoptar determinadas medidas de investigación en el territorio de un Estado Parte sin haber obtenido la cooperación de éste con arreglo a la Parte IX en el caso de que la Sala haya determinado, de ser posible teniendo en cuenta las opiniones del Estado de que se trate, que dicho Estado manifiestamente no está en condiciones de cumplir una solicitud de cooperación debido a que no existe autoridad u órgano alguno de su sistema judicial competente para cumplir una solicitud de cooperación con arreglo a la Parte IX“ Este es el único caso en que no se requiere del consentimiento del Estado para medidas coercitivas en el sistema puesto en marcha por el Estatuto, y se refiere a situaciones en las que no habría en los hechos autoridad competente que pudiera consentir ${ }^{12}$. Para Kleffner, la expresión "medidas de investigación" no incluiría por ejemplo la facultad de aprehender a una persona ${ }^{13}$. Otros autores estiman que sí, ya que la expresión no es restrictiva ${ }^{14}$. En los proyectos de Zutphen y del Comité Preparatorio de 1998 se preveía

and Jurisprudence, 1 (2003), pp. 214 ss. Como señala RASTAN, Rod, cit. (n. 2), p. 45:, "the Rome system should be seen as creating a covenant of undertakings between the individual state and the collective". Y añade: "[T]he treaty signed in Rome should be viewed not merely as the creation of a Court, but rather as the establishment of a System, a global system comprising a network of powers and duties between the ICC and nation-States".

${ }^{11}$ En el mismo sentido Rastan, Rod, cit. (n. 2), p. 438.

${ }^{12}$ No está lejos de la realidad Camargo, Pedro Pablo, Manual de Derecho Penal Internacional (Bogotá, Editorial Leyer, 2004), p. 134, cuando señala: "La parte IX del Estatuto es, sin duda, la más importante, puesto que sin la cooperación internacional y la asistencia judicial la Corte Penal Internacional sería un tribunal simbólico”. Wu Wei distingue entre las investigaciones de propia mano (las que realice directamente el Fiscal), y las investigaciones funcionales, para las que requiere de la colaboración de los Estados. Cfr. WeI, Wu. Die Rolle des Anklägers eines internationalen Strafgerichtshofs (Frankfurt am Main, Peter Lang Verlag, 2007), pp. 103 ss.

${ }^{13}$ KLefFner, Jann, Complementarity in the Rome Statute and National Criminal Jurisdictions (Oxford, Oxford University Press, 2008), p. 231. Más referencias en WeI, Wu, cit. (n. 12), pp.127 s.

${ }^{14} \mathrm{WeI}, \mathrm{Wu}$, cit. (n. 12), p. 122, con más referencias en p. 126: CRYER, Robert y otros, cit. (n. 9), p. 418. 
expresamente la posibilidad de que el Fiscal pudiera excepcionalmente aprehender a alguien o llevar a cabo otras medidas coercitivas. En definitiva, esas propuestas no se consideraron en el texto final. Esto es interpretado como prueba de que la adopción de medidas coercitivas no es posible, no pudiendo empero descartarse que simplemente se considerara innecesario mencionar esas medidas en detalle, puesto que quedarían abarcadas como "medidas de investigación". Cierto es sí, sin lugar a dudas, que el supuesto en que se posibilita esta acción es más restrictivo que en los proyectos mencionados. Bastaba en los proyectos que la oficina estatal que debía encargarse de recibir las solicitudes de cooperación no estuviera disponible o no funcionara ${ }^{15}$, hoy el requisito es que no exista "autoridad u órgano alguno" competente para dar curso a la solicitud.

Aparte de la antedicha excepción, la Corte depende de la acción estatal para actuar. Ya que no pretende reemplazar a la jurisdicción estatal, su Estatuto dispone una obligación general de cooperar para los Estados Partes (artículo 86) y ha negociado y suscrito acuerdos de cooperación con otros Estados y organizaciones internacionales, tanto gubernamentales como no gubernamentales. Estas últimas son especialmente relevantes, pues suelen tener presencia en las zonas de conflicto en las que por naturaleza la Corte realizará su labor.

En lo que sigue nos centraremos en la cooperación estatal, distinguiendo para nuestro análisis entre los Estados Partes del Estatuto y los que no lo son.

\section{Cooperación de los Estados Partes del "Estatuto de Roma” con la Corte Penal Internacional}

La cooperación está regulada en la parte IX del Estatuto de la Corte Penal Internacional, artículos 86 y siguientes, y las Reglas de Procedimiento y Prueba $^{16}$. Las disposiciones más importantes en materia de fijar obligaciones estatales de cooperación con la Corte Penal Internacional son los artículos 86 y 88 de su Estatuto. El primero de ellos obliga a los Estados Partes a cooperar plenamente con la Corte en la investigación y enjuiciamiento

${ }^{15}$ Cfr. el artículo 47 [26] párrafo 2 opción 2 (iii), el artículo 53 [29] (1) bis del proyecto Zutphen y artículo 54 párrafo 4 c) opción 2 (iii) y artículo 60 párrafo 2 del proyecto del Comité Preparatorio de 1998.

${ }^{16}$ Respecto de estas últimas, véase: GARTNER, Irene, The Rules of Procedure and Evidence on Co-operation and Enforcement, en FISCHER, Horst - KRESS, Claus - LuEDER, Sascha Rolf (editores), International and National Prosecution of Crimes under International Law, current developments, 2a. edición (Berlín, Berliner Wissenschaftsverlag, 2004), pp. 423 ss. 
de los crímenes internacionales de su competencia; y el segundo obliga a los Estados Partes a implementar procedimientos aplicables a todas las formas de cooperación que especifica la novena parte del Estatuto. Es de notar que ya en el proyecto de la Comisión de Derecho Internacional de 1994 se establecía la "obligación de cooperar". Luego, en el Comité Preparatorio de 1997, se vio la necesidad de que esta cooperación fuera plena (artículo 51) ${ }^{17}$. Antes la referencia al término "plenamente" no estaba, pero a cambio se especificaba que un Estado Parte no podía rehusar una solicitud de cooperación salvo por los motivos que el Estatuto prevé (artículo X). La versión del Comité Preparatorio de 1997 agregaba que las solicitudes deben ser cumplidas sin demora (injustificada). Esa última referencia explícita fue dejada de lado en definitiva ${ }^{18}$.

Luego de una breve revista a la obligación de implementar del artículo 88 del Estatuto de la Corte Penal Internacional, que es la única cuyo cumplimiento puede constatarse a priori con información pública y puede darnos una pauta acerca del compromiso de los Estados en cooperar plenamente con la Corte, nuestra atención se centrará en los mecanismos de acción de que se dispone para el caso de que un Estado incumpla su obligación de cooperar y en la importancia de contar con tales mecanismos jurídicos.

\section{Obligación del artículo 88 del "Estatuto de la Corte Penal Interna- cional'.}

La relevancia de la cooperación para el sistema complementario queda de manifiesto en que si se tiene presente que un Estado se hace parte del Estatuto de la Corte Penal Internacional adquiere la obligación de modificar su legislación interna sólo en dos aspectos: uno material, previendo como punibles las conductas que contra la administración de justicia previstas en el artículo 70 del Estatuto y otro, precisamente el que deriva de la obligación en comento de prever mecanismos para cumplir con todas las formas de cooperación previstas en la parte IX del Estatuto, conforme al artículo 88 del Estatuto de la Corte Penal Internacional ${ }^{19}$.

${ }^{17}$ Cfr. Bassiouni, M. Cherif, cit. (n. 7), II, pp. 604 ss.; Heilmann, Daniel, Die Effektivität des Internationalen Strafgerichtshofs (Baden-Baden, Nomos, 2006), p. 173; Misкowiak, Kristina, Consent, Complementarity and Cooperation (Copenhagen, DJOF Publishing, 2000), p. 60. La palabra "plenamente" fue agregada en el Comité Preparatorio de 1997.

${ }^{18}$ Cfr. Bassiouni, M. Cherif, cit. (n. 7), II, pp. 604 ss.

${ }^{19}$ El artículo 88 del Estatuto de la Corte Penal Internacional dispone que: "Los Estados Partes se asegurarán de que en el derecho interno existan procedimientos aplicables a todas las formas de cooperación especificadas en la presente parte". La importancia práctica de esta disposición, que queda de manifiesto con la experiencia de los tribunales ad hoc, es resaltada por NsERECo, Daniel, Cooperation with the Court on Matters 
Ya en el Comité Ad Hoc (1995) se resalta la importancia de que sea en el derecho y la jurisdicción nacionales donde se garanticen los derechos individuales respecto de las gestiones que se realicen en cada Estado. Previendo que en muchos casos esa es su misión constitucional y que pueden tener estándares más altos que los del derecho internacional, se prefiere dejar que cada Estado regule la materia ${ }^{20}$.

No es esta la ocasión de pasar revista a cada una de las formas de cooperación previstas en la parte IX del Estatuto: destacan la entrega -vocablo intencionadamente destinto de extradición, que implica la entrega de una persona de en Estado a otro (artículo 102) ${ }^{21}$ - y otros como la realización de inspecciones oculares, la identificación de objetos, la protección a víctimas y testigos, la solicitud de detención y entrega, la identificación e interrogación de personas, las notificaciones, la preservación de pruebas, etc. La parte IX del Estatuto no contiene una enumeración taxativa de formas de cooperación posibles, sino más bien una cláusula abierta en el artículo 97 letra l) ${ }^{22}$. Las formas de cooperación explicitadas en la parte IX del Estatuto de la Corte Penal Internacional son más bien un piso, pues, como bien apuntan Zahar y Sluiter, formas de cooperación importantes pueden no estar expresamente recogidas en él ${ }^{23}$.

A pesar de lo inequívoco de la disposición, la mayoría de los Estados Partes no cumplen con el artículo 88 del Estatuto de la Corte Penal Internacional. Pueden distinguirse, dentro de los Estados incumplidores, distintas situaciones:

a) Estados que no cuentan con implementación en lo absoluto. En el caso de estos Estados, los únicos datos ciertos con los que la Corte cuenta en caso de que se necesite solicitar su cooperación son los que entrega al momento de hacerse parte, conforme al artículo 87 párrafos 1 y 2 del Estatuto de la Corte Penal Internacional.

od Arrest and Surrender of Indicted Fugitives: lessons form the Ad Hoc Tribunals and National Jurisdictions, en DorIA, José y otros (editores), The Legal Regime of the ICC: Essays in Honour of Prof. I. P. Blishchenko (Leiden, Brill, 2009), pp. 975, 980. Cfr. al respecto, también: Herencia CARRASCO, Salvador, cit. (n. 2), p. 63 ss.

${ }^{20}$ Cfr. Bassiouni, M. Cherif, cit. (n. 7), II, p. 630.

${ }^{21}$ Cfr., específicamente respecto de esta forma de cooperación, KNoops, GeertJan Alexander, Surrendering to International Criminal Courts: Contemporary Practice and Procedures (Ardsley, Transnational Publishers, 2002).

${ }^{22} \mathrm{Si}$ bien esto parece ser negado por MAIKOwsKI, Tatjana, Staatliche Kooperationspflichten gegenüber dem Internationalen Strafgerichtshof (Berlin, Berliner Wissenschaftsverlag, 2002), p. 168, el texto del Estatuto es claro al respecto.

${ }^{23}$ Artículos 99 párrafo 1 letra e) y 93 párrafo 7 del Estatuto de la Corte Penal Internacional. ZAHAR, Alexander - SLUITER, Göran, International Criminal Law (Oxford, Oxford University Press, 2008), p. 472. 
i) Artículo 87 párrafo 1 del Estatuto de la Corte Penal Internacional: el Estado debe comunicar a la Corte el canal por el que desea que se haga la solicitud. (Ministerio de Asuntos Exteriores, Procuraduría, etc.).

ii) Artículo 87 párrafo 2 del Estatuto de la Corte Penal Internacional: el Estado debe señalar a la Corte el idioma en el que desea que se haga la comunicación.

En esta situación, de no contar con legislación de cooperación con la Corte Penal Internacional, se encuentran todos los hispanoamericanos que han ratificado el Estatuto, salvo Perú y Argentina. Ello puede ocasionar que, llegado el momento de cumplir con una solicitud concreta de cooperación, su cumplimiento resulte engorroso. Incluso puede suceder que algún funcionario de un Estado que no considere directamente aplicable el Estatuto y no tenga legislación de implementación, se niegue a dar curso a alguna solicitud en virtud del principio de derecho público que rige a la administración -según el cual sólo puede hacer aquello para lo que está expresamente facultado- sin perjuicio de que el Estado como tal se encuentre obligado y no le esté permitido alegar razones de derecho interno para incumplir con su obligación internacional.

b) Estados que cuentan con una cláusula genérica. Existen algunos Estados que han modificado de su derecho interno, pero simplemente declarando aplicables regímenes de cooperación internacional ya vigentes (es el caso de Bosnia Herzegovina). Este modo de proceder dista también del cumplimiento cabal de la obligación del artículo 88 del Estatuto de la Corte Penal Internacional, que señala que deben preverse procedimientos para cada una de las formas de cooperación especificadas en la parte IX del Estatuto. Si bien muchas de las formas de cooperar con la Corte previstas en la parte IX del Estatuto son homologables a formas de cooperación con un Estado extranjero, no equivalen exactamente.

c) Estados que han dictado legislación específica. Entre los Estados que tienen implementados procedimientos de cooperación hay distintas formas de operar: algunos lo han hecho mediante modificaciones a su código procesal penal, por lo general incluyendo la materia en un apartado especial de la ley (Perú, Polonia, Latvia, Francia) o simplemente señalando que se aplican los mismos canales ya vigentes para la cooperación horizontal. Otros han dictado leyes especiales, ya sea que la ley se refiera sólo a la cooperación o se trate de una ley que implemente también los crímenes de Derecho Internacional. Ejemplos de Estados con legislación interna específica y separada son Trinidad y Tobago, Noruega, Malta, Luxemburgo, Georgia, Croacia, Bélgica, Austria, el Reino Unido, Suiza, España, Sudáfrica, Nueva Zelanda, Alemania, Dinamarca, Canadá, Aus- 
tralia, Letonia, Holanda, Liechtenstein, Finlandia, Lituania y Suecia ${ }^{24}$.

En general los Estados que cuentan con leyes especiales se encargan de regular de mejor manera las formas de cooperación específicamente previstas en el Estatuto, lo que por regla general hace más expedita la cooperación en un caso concreto. Sin embargo, el grado de cumplimiento de la obligación del artículo 88 del Estatuto de la Corte Penal Internacional dependerá del contenido de cada ley específica.

En general, en estas leyes se señala qué autoridades son competentes para ejecutar las solicitudes y cómo ha de procederse en cada caso, lo que en definitiva facilita la cooperación porque existe ya un camino a seguir. Por ejemplo, para la ejecución directa de medidas (que vayan equipos de investigadores e interroguen directamente a testigos, verbigracia), algunos Estados exigen simplemente una notificación (Austria), otros que se les solicite autorización (Suiza), otros que esté un funcionario del Estado presente en la diligencia.

En suma, si un Estado decide ratificar el Estatuto de la Corte Penal Internacional, ciertamente sería lo adecuado que también se ocupara de implementar la forma de cumplir las obligaciones que el tratado impone a sus partes en materia de cooperación (directamente la de implementar, indirectamente la de cooperar plenamente). Respecto de este último punto, revisar la legislación sobre implementación resulta interesante para tener un panorama, pero ciertamente no es decisivo, ya que aún un Estado con una implementación modelo podría, en un caso concreto, incumplir con su obligación de cooperar con la Corte.

\section{El incumplimiento de la obligación de cooperar de la Corte y sus con-} secuencias.

No existe una consecuencia expresamente prevista en el Estatuto para el incumplimiento de las obligaciones de cooperación. Así por ejemplo, los Estados que no prevén procedimientos en su derecho interno para todas las formas de cooperación previstas en la parte IX del Estatuto no se ven expuestos a sanción alguna.

Sólo en casos específicos el Estatuto prevé un procedimiento a seguir en caso de incumplimiento de la obligación de cooperar. Esto que a primera vista puede aparecer como una debilidad ${ }^{25}$, implica en la práctica

${ }^{24}$ La legistación de implementación de varios Estados puede revisarse desde la página web de la Corte Penal Internacional, http://www.icc-cpi.int/ [visitada el 24 de enero de 2009].

${ }^{25}$ Cfr. Heilmann, Daniel, cit. (n. 17), p. 174; Kaul, Hans-Peter, The International Criminal Court - Its Relationship to Domestic Jurisdictions, en STAHN, Carsten SLUITER, Goeran (editores), The Emerging Practice of the International Criminal Court (Leiden, Martinus Nijhoff, 2009), pp. 31, 34. 
que se aplican las normas generales sobre responsabilidad internacional. Resulta altamente dudoso que un sistema específico de sanciones fuera a aplicarse en la práctica o fuera a incentivar que los Estados se hagan parte del Estatuto de la Corte Penal Internacional. De allí que la falta expresa de sanción no es tan criticable como pudiera aparecer a primera vista. Para lograr efectivamente la cooperación se requiere de la buena voluntad de los Estados en el caso concreto. Un sistema de incentivos y consultas es, en estas circunstancias, más efectivo que uno de sanciones.

a) Casos de incumplimiento en los que se prevé un procedimiento a seguir. En este punto, la disposición clave es el artículo 87 párrafo 7 del Estatuto de la Corte Penal Internacional: "Cuando, en contravención de lo dispuesto en el presente Estatuto, un Estado Parte se niegue a dar curso a una solicitud de cooperación formulada por la Corte, impidiéndole ejercer sus funciones y atribuciones de conformidad con el presente Estatuto, ésta podrá hacer una constatación en ese sentido y remitir la cuestión a la Asamblea de los Estados Partes o al Consejo de Seguridad, si éste le hubiese remitido el asunto".

La disposición contempla como primer requisito para su aplicación que exista una falta de cooperación que consista en negarse a dar curso a una solicitud concreta que haya sido formulada por la Corte ${ }^{26}$. En segundo término, la falta de cooperación ha de producirse en contravención al Estatuto. Esta condición resulta relevante, pues hay varias causas por las que un Estado podría legítimamente aplazar el cumplimiento de una solicitud o negarse a cumplirla en la manera solicitada ${ }^{27}$.

Los casos en los que los Estados están facultados para no cooperar (o no hacerlo de inmediato) son los siguientes:

i) Si está pendiente una impugnación a la admisibilidad del asunto. Según el artículo 95 del Estatuto de la Corte Penal Internacional, los Estados en este caso pueden aplazar el cumplimiento de la solicitud. Conforme al artículo 19 del Estatuto la admisibilidad de un asunto puede ser impugnada

${ }^{26}$ En palabras de Cid MuÑoz, María Isabel, cit. (n. 8), p. 85: "La obligación a cooperar es activada por las solicitudes de la Corte”. Sin embargo, más bien es un supuesto en el que se prevé un procedimiento a seguir por el incumplimiento. Por último, el incumplimiento debe impedir a la Corte ejercer sus funciones y atribuciones.

${ }^{27}$ Cfr., al respecto, Herencia Carrasco, Salvador, cit. (n. 2), pp. 62 ss. Esta multiplicidad de excusas válidas son parte de las razones por lo que la doctrina está conteste en que el régimen de cooperación entre los Estados de la Corte Penal Internacional no es totalmente vertical (conforme a la terminología de la Decisión Subpoena en el caso Blaskic, ante el TPIY), sino que tiene importantes elementos que corresponden más bien a un sistema de cooperación horizontal (entre Estados). Cfr., a saber, CRYer, Robert at al., cit. (n. 9), pp. 405 ss. 
por el imputado, un Estado que conoció o esté conociendo del asunto o el Estado que haya reconocido la jurisdicción de la Corte sólo para un crimen determinado, conforme al artículo 12 del Estatuto. La oportunidad para impugnar es antes del juicio o a su inicio, excepcionalmente procede también después (artículo 19 párrafo 4 del Estatuto de la Corte Penal Internacional). Vale decir, la Corte puede requerir y seguramente requerirá cooperación antes de que precluya la posibilidad de impugnar.

ii) Cuando un Estado tenga información o documentos de terceros entregados bajo confidencialidad antes de que se solicite específicamente la cooperación debe recabar el consentimiento de su autor (artículo 73 del Estatuto de la Corte Penal Internacional).

iii) Si existen solicitudes concurrentes: artículo 90 del Estatuto de la Corte Penal Internacional regula cuál prefiere.

iv) El Estado puede asimismo alegar asuntos de seguridad nacional conforme a los artículos 72 y 93 párrafos 4 y 6 del Estatuto de la Corte Penal Internacional.

v) Por último, un Estado Parte puede legítimamente no dar curso a una solicitud de cooperación conforme al artículo 93 párrafo 3 del Estatuto de la Corte Penal Internacional si una medida que se le solicita está prohibida por un principio de derecho que es de aplicación general y es fundamental. La introducción de esta regla habría tenido por finalidad el asegurar que los Estados no pudieran apoyarse, para denegar válidamente la cooperación, en normas procesales de su derecho interno que no sean manifestación de un principio con estas características ${ }^{28}$.

Para que exista el incumplimiento al que se refiere el artículo 87 párrafo 7 del Estatuto de la Corte Penal Internacional, se requiere además que este incumplimiento tenga como consecuencia que la Corte se vea impedida de ejercer su jurisdicción sobre los crímenes más graves de trascendencia internacional.

Todo eso ha de ser constatado por la Corte. El primer paso para tomar medidas por un incumplimiento de estas características es que exista un hallazgo judicial del incumplimiento de esa obligación. El fiscal no puede remitir el asunto directamente a la Asamblea de Estados Partes o al Consejo de Seguridad ${ }^{29}$.

${ }^{28} \mathrm{Cfr}$. Мосносноко, Phakiso, International Cooperation and Judicial Assistence, en LeE, Roy (editor). The International Criminal Court, the Making of the Rome Statute (Hague, Kluwer, 1999), p. 305, 309.

${ }^{29}$ Desde el informe del Comité Preparatorio de 1997 hasta el informe del Comité Preparatorio de 1998. El proyecto de Estatuto de la Corte Penal Internacional contuvo una propuesta que incluye, al final del artículo que reza "so that necessary measures may be taken to enable the Court to exercise its jursdiction”, expresándose 
b) Consecuencias del incumplimiento. El Estatuto no prevé sanciones a aplicar. Más bien, ante el incumplimiento lo único que se prevea que haga es constatarlo, remitiendo luego el asunto a la comunidad internacional, sea en forma de la Asamblea de Estados Partes del Consejo de Seguridad de Naciones Unidas ${ }^{30}$. Se afirma entonces que el tribunal no tiene posibilidad de aplicar directamente sanciones, a menos que se pretenda fundamentar tal aplicación en la doctrina de los "poderes implícitos" ("implied powers"). Se trata de una doctrina que está aceptada en el derecho internacional, si bien su alcance no está exento de controversia $^{31}$. Conforme a ella, una organización internacional está dotada de todos los poderes necesarios para cumplir con sus fines, aunque estos no estén expresados en su instrumento constitutivo. Puede discutirse su aplicación respecto de la Corte, pero se llegaría en todo caso al punto en que, de requerirse acciones coercitivas, la Corte depende de los Estados para ejecutar sus decisiones.

Con todo, no es menos cierto que todos los tribunales internacionales comparten dificultades de imperio, y, como apunta Wei, si bien este puede ser un problema para el accionar de la Corte, el hecho de que se prevean vías de acción ante un incumplimiento -aunque disten de garantizar efectividad-implica reconocer más facultades a la Corte que las que tiene en este ámbito, a saber, la Corte Internacional de Justicia ${ }^{32}$.

El artículo 87 del Estatuto de la Corte Penal Internacional prevé dos vías de acción posibles luego de la constatación de un incumplimiento: envío a la Asamblea de Estados Partes o al Consejo de Seguridad ${ }^{33}$.

en una nota al pie del proyecto Zutphen que el asunto de las "necessary measures" requiere de más discusión Cfr. BASSIOUNI, M. Cherif, cit. (n. 7), II, pp. 613 ss.

${ }^{30}$ Rastan, Rod, cit. (n. 3), p. 170.

${ }^{31}$ Cfr. al respecto: Engstrom, Viljam, Implied Powers of International Organizations: on the Character of a Legal Doctrine, en Finnish Yearbook of International Law, 24 (2003), pp. 129 ss.; SKUBISZEWSKI, Krzysztof, Implied Powers of International Organizations, en DinsteIn, Yoram (editor), International Law at a Time of Perplexity (Dordrecht, Martinus Nijhoff 1989), pp. 855 ss.; Rama-MonTALdo, Manuel, International Legal Personality an Implied Powers of International Organizations, en British Yearbook of International Law, 44 (1970), 111, pp. 147 ss.

${ }^{32} \mathrm{WEI}, \mathrm{Wu}$, cit. (n. 12), p. 100. Para algunos autores esto es una consecuencia de que el tribunal haya sido creado otorgándole personalidad jurídica propia, independiente de (aunque relacionada con) las Naciones Unidas. Cfr., por todos y con más referencias: JACOBS, Dov, A Samson at the International Criminal Court: The Powers of the Prosecutor at the Pre-Trial Phase, en The Law and Practice of International Courts and Tribunals, 6 (2007), pp. 336 s.

${ }^{33}$ Esta es una manifestación más de lo que varios autores denominan "dos cortes en una" o una "corte bifronte" (Janus-headed), haciendo alusión al régimen general de la Corte versus el régimen especial que se aplica cuando es el Consejo de Segu- 
i) La remisión del incumplimiento al Consejo de Seguridad, que sucederá en los casos en que el Consejo haya remitido la situación de que se trata a la Corte conforme al artículo 13 b) de su Estatuto. El Consejo podrá tomar las medidas a las que lo faculte el capítulo $7^{\circ}$ de la Carta de Naciones Unidas (relativo a la acción en casos de amenazas a la paz, quebrantamientos de la paz o actos de agresión) o su capítulo $4^{\circ}$ (sobre arreglo pacífico de controversias), que podrían consistir en autorizar u ordenar que los Estados miembros de Naciones Unidas tomen medidas. Debe tenerse presente empero que por esta vía no se garantiza que se tome acción alguna, ya que el Consejo de Seguridad podría no tomar medida alguna ${ }^{34}$. De hecho, el Convenio de cooperación entre la Corte y Naciones Unidas prevé expresamente la posibilidad de que el Consejo proceda de ese modo ${ }^{35}$.

El informe del Comité Preparatorio de 1996 contenía una propuesta de regulación distinta, que en caso de incumplimiento preveía que la Corte podía solicitar al Consejo de Seguridad "to take the measures neccesary to enable the Court to exercise its jurisdiction, in relation to both States Parties to this Statute, or Status not Parties". Con todo, en una nota al pie se hace presente que varias delegaciones discrepan respecto del rol que ha de cumplir el Consejo de Seguridad, considerando que no debe estar envuelto de modo alguno en el trabajo de la Corte ${ }^{36}$. En definitiva se acordó la disposición del modo ya descrito.

ii) La remisión de incumplimiento a la Asamblea de Estados Partes es la vía prevista en el Estatuto en los casos en los que la situación objeto de

ridad de Naciones Unidas quien le remite una situación. Véase, por todos: KaUL, Hans-Peter - KRESS, Klaus, Jurisdiction and cooperation in the Statute of the International Criminal Court: Principles and Compromises, en Yearbook of International Humanitarian Law, 2 (1999), pp. 143, 172.

${ }^{34}$ ZaHAR, Alexander - Sluiter, Göran, cit. (n. 23), pp. 475 s.

${ }^{35}$ Acuerdo de relación entre la Corte Penal Internacional y las Naciones Unidas Aprobada por consenso en la tercera sesión plenaria, celebrada el 7 de septiembre de 2004 Resolución ICC-ASP/3/Res.1, artículo 17 párrafo 3: "En los casos en que el Consejo de Seguridad haya remitido a la Corte una cuestión y la Corte encuentre, de conformidad con el párrafo 5 b) o el párrafo 7 del artículo 87 del Estatuto, que un Estado se niega a cooperar con la Corte, esta informará o remitirá la cuestión al Consejo de Seguridad, según el caso, y el Secretario transmitirá al Consejo de Seguridad, por conducto del Secretario General, la decisión de la Corte, junto con la información pertinente en el asunto. El Consejo de Seguridad, por conducto del Secretario General, informará a la Corte, por conducto del Secretario, acerca de las medidas adoptadas en esas circunstancias, si las hubiere".

${ }^{36}$ Cfr. Bassiouni, M. Cherif, cit. (n. 7), II, p. 618. 
investigación por parte de la Corte le fuera remitida por un Estado Parte o el Fiscal ha iniciado una investigación de motu proprio.

Conforme al artículo 112 párrafo 2 letra f), la Asamblea "examinará" el incumplimiento. Cabe destacar que si bien la Asamblea existe para la Corte, no está entre sus órganos conforme al artículo 34 de su Estatuto.

En la Asamblea se podría decidir sobre incumplimientos materia de cooperación por mayoría de dos tercios ${ }^{37}$. Como el Estatuto nada dice, será la Asamblea la que, en su caso, decida las medidas a tomar (a saber, condenar la violación, sanciones diplomáticas o económicas ${ }^{38}$. Con todo, siguiendo a Meissner estas medidas solamente podrían tener el carácter de recomendaciones, ya que la Asamblea no tendría facultades para resolver de manera vinculante. De allí que este sistema no excluya al de la responsabilidad internacional en general ${ }^{39}$.

Zahar y Sluiter estiman, por otra parte, que las medidas que podría llegar a tomar la Asamblea pueden ser similares a las previstas para los casos en los que los Estados dejan de cumplir con sus obligaciones financieras, como por ejemplo disponer que pierdan su derecho a voto ${ }^{40}$. Esta clase de medidas podrían ser especialmente contraproducentes si lo que se busca en definitiva es obtener la cooperación del Estado de que se trate. Por otra parte, teniendo en consideración que la Asamblea tiene las mismas Facultades en los casos en los que el incumplidor sea un Estado no parte que haya celebrado un acuerdo de cooperación con la Corte (conforme al artículo 87 párrafo $5 \mathrm{~b}$ ) del Estatuto) es claro que las medidas a adoptar pueden ir más allá de los derechos de los Estados dentro de la Asamblea.

Existe cierto consenso en cuanto a que derivar el asunto a la Asamblea de Estados Parte no es lo más efectivo, tanto porque no se reúne con la frecuencia suficiente como para que su actuar pueda resultar eficaz en todos los casos, como porque, debido al gran número de Estados Partes, es previsible que sería difícil llegar a consenso para decidir sobre medidas concretas ${ }^{41}$. sobre todo si estas no se encuentran reguladas específicamente. Se sostiene además que en ningún caso podría tomar medidas de fuerza ${ }^{42}$.

Con todo la Asamblea de Estados Partes parece estar dispuesta a asumir el desafío de apoyar y garantizar la cooperación necesaria para que la Corte pueda operar con acciones concretas, como utilizar los instrumen-

${ }^{37}$ Cfr. Meissner, Jörg, cit. (n. 2), p. 268.

${ }^{38}$ Maikowski, Tatjana, cit. (n. 22), p. 275.

${ }^{39}$ Meissner, Jörg, cit. (n. 2), p. 269.

${ }^{40}$ ZAHAR, Alexander - Sluiter, Göran, cit. (n. 23), p. 475.

${ }^{41} \mathrm{WeI}, \mathrm{Wu}$, cit. (n. 12), p. 101, con más referencias.

${ }^{42}$ Bujosa Vadell, Lorenzo, La cooperación procesal de los Estados con la Corte Penal Internacional (Barcelona, Atelier 2008), p. 217. 
tos coercitivos que eventualmente existan en organizaciones regionales e internacionales, de ser necesario ${ }^{43}$.

Existe consenso en que, si bien el Estatuto de la Corte Penal Internacional no lo prevé expresamente, el Consejo de Seguridad de Naciones Unidas también podría tomar medidas contra Estados que no cooperen con la Corte Penal Internacional, haciendo uso de las facultades generales que le da la Carta de Naciones Unidas, con prescindencia de que la Corte les remita el asunto del incumplimiento de la obligación de cooperar ${ }^{44}$. Esto se sigue de un razonamiento a maiore ad minus: ya que ante la comisión de crímenes internacionales el Consejo de Seguridad está facultado para establecer tribunales internacionales, con mayor razón está facultado para tomar medidas contra quienes no cooperen en la investigación y persecución de estos crímenes por un tribunal internacional existente. Esta idea cobra fuerza si se tiene presente que el preámbulo del propio Estatuto de la Corte reconoce expresamente que los crímenes de competencia de la Corte Penal Internacional constituyen una amenaza para la paz, la seguridad y el bienestar de la humanidad ${ }^{45}$. Así las cosas, para Rastan el Consejo de Seguridad incluso podría establecer, para los Estados miembros de $\mathrm{Na}$ ciones Unidas, obligaciones más gravosas o distintas de las contenidas en el Estatuto de la Corte para sus Estados Parte, de acuerdo al artículo 103 de la Carta de Naciones Unidas ${ }^{46}$.

Los autores que han estudiado más acuciosamente el tema de la cooperación están de acuerdo en que -más allá de la Asamblea de Estados Parteslos Estados, ya sea individualmente o por medio de otras organizaciones,

${ }^{43}$ Cfr. el "Informe de la Mesa sobre Cooperación”, Asamblea de Estados Partes, sexto período de sesiones, Nueva York, 30 de noviembre a 14 de diciembre de 2007, ICC-ASP/6/21, párrafo 77. "Los Estados Partes deberían siempre promover las actividades generales y especificas de la Corte en organizaciones regionales e internacionales. Ello puede hacerse mediante resoluciones, declaraciones y otras formas de apoyo político, asi como de diferentes formas de asistencia técnica. Estos instrumentos se pueden también utilizar para facilitar la detención y entrega, recurriendo en último extremo a la utilización de los instrumentos coercitivos disponibles en algunas de estas organizaciones" Cfr. también el párrafo 71.

${ }^{44}$ Así, a saber, Heilmann, Daniel, cit. (n. 17), p. 176; Steinberger-Fraunhofer, Theresa. Internationales Strafgerichtshof und Drittstaaten (Berlín, Dunker \& Humblot, 2008), p. 225 (cita en el mismo sentido a Cassesse y Zimmermann); WeI, Wu, cit. (n. 12), p. 103.

${ }^{45}$ Así lo expresa también Rastan, Rod, cit. (n. 3), p. 170.

${ }^{46}$ Artículo 103: "En caso de conflicto entre las obligaciones contraidas por los Miembros de las Naciones Unidas en virtud de la presente Carta y sus obligaciones contraídas en virtud de cualquier otro convenio internacional, prevalecerán las obligaciones impuestas por la presente Carta" 
pueden tomar medidas ${ }^{47}$. Se pronuncian también a favor de la factibilidad de sanciones colectivas (económicas, por ejemplo) ${ }^{48}$. Para comprender el fundamento de estas medidas -que está en las normas generales de derecho internacional no exclusivas del derecho penal internacional- es menester acudir al siguiente razonamiento: la Corte Penal Internacional se ocupa de investigar y juzgar los crímenes más graves contra el derecho internacional, que importan los atentados más graves en contra de los bienes jurídicos más fundamentales para la comunidad internacional (de allí que se los haya penalizado). La Corte sólo actúa en supuestos en los que, de no hacerlo, esos crímenes no serían investigados y juzgados adecuadamente. Siguiendo este razonamiento, si no se coopera con la Corte, ésta no podrá actuar adecuadamente, lo que derivará en no combatir estas conductas que en virtud del derecho internacional son punibles. Esta no sería una conducta permitida para un sujeto de derecho internacional público, como lo son los Estados, sino que por el contrario iría no sólo contra el tratado, sino también en contra de los intereses de cada Estado individualmente considerado, como sujeto de derecho internacional público y parte de la comunidad internacional.

Algunos autores estiman, siguiendo este razonamiento, que los Estados Parte están facultados para adoptar represalias, pues la obligación de cooperar tendría el carácter de erga omnes partes ${ }^{49}$. Wei, por su parte, se manifiesta en contra de la posibilidad de que un Estado pueda tomar medidas individuales, ya que en su opinión la derivación del asunto a "la Asamblea" como colectivo parece proscribir la posibilidad ${ }^{50}$. El punto está en determinar si la falta de cooperación de un Estado con la Corte violenta o no los derechos de cada Estado, y si es necesario esto último para justificar las medidas individuales o si basta con que se lesionen intereses. $\mathrm{Al}$ respecto, tomando como guía el proyecto sobre responsabilidad de los Estados de la

${ }^{47}$ Cfr., en ese sentido, a saber, Kress, Claus - Prost, Kimberly - Wilkizki, Peter, cit. (n. 4), pp. 1530 s.; Maikowski, Tatjana, cit. (n. 22), p. 275. Para esta última autora, los Estados Partes pueden tomar medidas unilaterales aun sin que exista una recomentación de la Asamblea de Estados Partes (ej. represalias, remisión a la Corte Internacional de Justicia, demás medios pacíficos de resolución de conflictos).

${ }^{48} \mathrm{WeI}, \mathrm{Wu}$, cit. (n. 12), pp. 100 s.; en un sentido análogo, Bruer-Schaefer, Aline, Der Internationales Strafgerichtshof. Die Internationale Strafgerichtsbarkeit im Spannungsfeld von Recht und Politik (Frankfurt am Main, Peter Lang Verlag, 2001), p. 283. En el mismo sentido, y con más referencias, KAUL, Hans-Peter - KrESS, Klaus, cit. (n. 33), pp. 143, 169 s.: y Bujosa VAdell, Lorenzo, cit. (n. 42), pp. 217 s.

${ }^{49}$ Maikowski, Tatjana, cit. (n. 22), pp. 268 y 275. En el mismo sentido Kress, Claus - Prost, Kimberly - Wilkizki, Peter, cit. (n. 4), p. 1530; los sigue Quesada AlCALÁ, Carmen, cit. (n. 5), pp. 460 s.

${ }^{50} \mathrm{WEI}, \mathrm{Wu}$, cit. (n. 12), p. 102. 
Comisión de Derecho Internacional de Naciones Unidas $(2001)^{51}$ estamos ante un hecho internacionalmente ilícito del Estado cuando una acción u omisión es atribuible a algún Estado conforme al derecho internacional y constituye una violación a una obligación internacional del Estado (artículo 2). Concurriendo ello, un Estado puede tomar medidas en contra de este hecho ilícito aunque no haya sido lesionado directamente por la medida. Por otra parte, el texto del proyecto presenta como opciones que la falta haya lesionado directamente a otro Estado, que la obligación exista con relación a la comunidad internacional en su conjunto (lo que se arguye frecuentemente pero no es completamente pacífico en el caso en comento) o que exista respecto de un grupo de Estados del que el Estado que invoca es parte ${ }^{52}$.

\section{CoOperación de los Estados QUe nO SON PARTES DEL "Estatuto de la Corte Penal Internacional"}

Un Estado que no es parte del Estatuto de la Corte Penal Internacional puede encontrarse en distintos supuestos por lo que respecta al examen de si existe alguna obligación de cooperar con la Corte Penal Internacional ${ }^{53}$ :

i) Puede ser que se trate de un Estado que no es parte del Estatuto de la Corte, pero que haya consentido formalmente, mediante declaración depositada en poder del Secretario de la Corte, en que la Corte ejerza su competencia respecto de un crimen específico. En este supuesto, conforme al artículo 12 párrafo 3 del Estatuto, "el Estado aceptante cooperará sin demora ni excepción de conformidad con la parte IX” (la parte del Estatuto dedicada a la cooperación).

ii) Un Estado que no es parte del Estatuto puede celebrar un acuerdo de cooperación con la Corte, según lo prevé en artículo 87 párrafo 5 del Estatuto de la Corte Penal Internacional. Queda entonces obligado a cooperar en los términos del acuerdo. Si no lo hace, la Corte podría informar a la Asamblea de Estados Parte o al Consejo de Seguridad de Naciones Unidas, si éste le hubiere remitido el asunto. Aquí queda claro que la Asamblea de Estados Parte puede tomar medidas que van más allá

${ }^{51}$ Cfr. Naciones Unidas, Doc. A/CN.4.L.602/ Rev.1*.

${ }^{52}$ Respecto a la aplicabilidad de estas disposiciones a la cooperación de los Estados con la Corte, cfr. Kress, Claus - Prost, Kimberly - Wilkizki, Peter, cit. (n. 4), pp. $1528 \mathrm{~s}$.

${ }^{53}$ En todos estos casos existen asuntos de difícil solución en cuanto a determinar si la obligación de cooperar es idéntica a la que tienen los Estados Partes (por ejemplo, si abarca la obligación de prever legislación de cooperación). Cfr. al respecto ZAHAR, Alexander - Sluiter, Göran, cit. (n. 23), pp. 466 s. 
de sus derechos dentro de la Asamblea, puesto que los Estados no parte carecen de ellos.

iii) Puede también darse el caso de que la Corte esté llevando a cabo una investigación o enjuiciamiento en virtud de una remisión del Consejo de Seguridad de Naciones Unidas conforme a lo dispuesto en el capítulo $7^{\circ}$ de la Carta de Naciones Unidas (sobre el mantenimiento de la paz y la seguridad internacionales), según lo dispuesto en el artículo 13 letra b) del Estatuto. En este supuesto, lo usual será (como por lo demás ya ha ocurrido respecto de la remisión de la situación de Sudán en la resolución 1593 de 2005), la misma resolución que remite el asunto a la Corte "decide" que los Estados involucrados en el conflicto deben cooperar y "exhorta" a los demás a hacerlo también. Con ello, a lo menos todos los Estados Partes de Naciones Unidas se verían obligados a cooperar con la Corte en estos casos, aunque no sean partes del Estatuto de la Corte Penal Internacional. La fuente de la obligación sería entonces ya no el Estatuto, sino la resolución. Es más, para Heilmann si la resolución prevé el deber de los Estados de cooperar con la Corte, dicha obligación implicaría, para los Estados que no sean parte del Estatuto, el deber de celebrar convenios de cooperación con la Corte ${ }^{54}$. En este supuesto, en incumplimiento de la obligación de cooperar puede ser informada al Consejo de Seguridad.

iv) Puede darse también el caso de un Estado que denuncia el tratado. Si eso sucede, la denuncia surtirá efecto un año después de la fecha en que se notifique, a menos de que en ella se contenga un plazo ulterior. Con todo, "[1] a denuncia no obstará a la cooperación con la Corte en el contexto de las investigaciones y los enjuiciamientos penales [...] que se hayan iniciado antes de la fecha en que la denuncia surta efecto" (artículo 127 del Estatuto).

v) En fin, puede suceder que un Estado no Parte, encontrándose fuera de todas las hipótesis anteriores, reciba una solicitud de cooperación de la Corte.

En los supuestos i) a iv) la obligación de cooperar es clara, pudiendo variar su fuente y alcances según los casos. En el último (v.), parte relevante de la doctrina que trata el tema se manifiesta favoreciendo la opinión de

${ }^{54}$ Heilmann, Daniel, cit. (n. 17), p. 182. Maikowski, Tatjana, cit. (n. 22), p. 265, postula que aunque la resolución que remite una situación a la Corte nada diga respecto de la cooperación, los Estados Partes de Naciones Unidas quedarían obligados a cooperar con la Corte. Heilmann, Daniel, cit. (n. 17), p. 180, opina, en cambio, que no puede colegirse tal obligación tácita de cooperar por la sola remisión de un asunto ante la Corte. Un argumento convincente a su favor es que esta interpretación le da sentido al artículo 87.5 b), que de lo contrario sería superfluo en la parte en que se refiere a situaciones remitidas por el Consejo de Seguridad. 
que estos Estados tienen también la obligación de cooperar con la Corte $e^{55}$. Claramente aquí la obligación no deriva del Estatuto ${ }^{56}$, sino que para fundamentarla es menester acudir al mismo razonamiento que sirve para justificar medidas unilaterales por parte de los Estados en caso de incumplimiento de la obligación de cooperar por un Estado Parte (véase más arriba). Una variante de esta postura consiste en entender que la obligación de cooperar con la Corte Penal Internacional como una manifestación del deber de proteger $^{57}$. Por último, algunos autores exponen la posibilidad de que otros convenios puedan implicar la obligación de cooperar con la Corte Penal Internacional ${ }^{58}$.

\section{V. ¿PODRÍA SER MÁS EFECTIVO UN RÉGIMEN DE COOPERACIÓN MÁS ESTRICTO?}

Dada la estructura complementaria del sistema de justicia penal internacional desde el que opera la Corte Penal Internacional, no es claro que ella tenga poderes sancionatorios frente a los Estados que incumplen con sus obligaciones en materia de cooperación, y aunque los tuviera, dependería de los propios Estados para su ejecución. Por otra parte, la experiencia de los tribunales ad hoc nos señala que el hecho de que exista un sistema de sanciones del que echar mano (en el caso de esos tribunales, las medidas conforme al capítulo $7^{\circ}$ de la Carta de Naciones Unidas) no necesariamente implica el que la cooperación sea más efectiva. Ha probado ser más efectiva la acción de incentivos de la comunidad internacional ${ }^{59}$, y se requiere más bien que la comunidad internacional muestre unidad en

${ }^{55}$ Ubéda, Muriel, cit. (n. 2), pp. 951 ss.; Quesada Alcalá, Carmen, cit. (n. 5), pp. 406 ss.

${ }^{56}$ Como apunta Heilmann, Daniel, cit. (n. 17), p. 177, terceros Estados no pueden ser obligados por un tratado sin su consentimiento.

${ }^{57}$ Sobre el particular cfr. RaStan, Rod, cit. (n. 3), pp. 169 ss.

${ }^{58}$ Cfr. Bujosa Vadell, Lorenzo, cit. (n. 42), p. 1523; La Rosa, Anne Marie, Les Forces Multinationales et l'Obligation de Coopérer avec les Tribunaux Internationaux sous l'Angle de l'Arrestation, en Ascencio, Hervé - Decaux, Emmanuel - Pellet, Alain (directores), Droit International Pénal (París, Pedone, 2000), pp. 690 ss.; Palmisano, Giuseppe, cit. (n. 5), pp. 352 ss., concluye que en algunos casos sí (ej. genocidio p. 354), otros no. Cfr. asimismo Quesada AlCAlÁ, Carmen, cit. (n. 5), p. 406 ss., quien se apoya en los tratados que prohíben los crímenes, en particular el convenio sobre el genocidio y el referido al apartheid, que en su texto hacen referencia a un tribunal internacional, lo que obligaría a sus Estados Partes a cooperar con la Corte en lo que sea necesario cuando se ocupe de esta clase de crímenes.

${ }^{59}$ Cfr. JACOBS, Dov, cit. (n. 32), pp. 337 s.; RASTAN, Rod, cit. (n. 3), pp.167 s. 
reprochar los incumplimientos de la obligación de cooperar con la Corte ${ }^{60}$. Así las cosas, en definitiva, para poder contar un sistema de cooperación más efectivo, lo más atingente parece ser el informar adecuadamente a la opinión pública acerca del actuar de la Corte, de modo que para un Estado dado, en un momento dado, aparezca como impresentable el no cooperar ${ }^{61}$. Como apunta Bujosa Vadell, la opción que en la actualidad aparece más prudente es la de reforzar la auctoritas de los órganos de la Corte ${ }^{62}$. En este mismo contexto, entender las obligaciones de los Estados en materia de cooperación y su importancia fundamental para el buen funcionamiento del sistema resulta ser una manera de asegurar esa cooperación ${ }^{63}$.

\section{CONCLUSIONES}

Es sabido que la cooperación puede llegar ser el gran talón de Aquiles de la Corte, que sin la cooperación de los Estados no puede trabajar. Piénsese en la gran dificultad logística de las investigaciones (en lugares lejanos que son además zonas de conflicto) y los procedimientos. Es conocida la figura, ideada por Cassese, de representar a los tribunales internacionales como gigantes, que sin la ayuda de los Estados carecen de manos y piernas, es decir, no pueden actuar.

Los Estados Partes del Estatuto de la Corte Penal Internacional, así como al menos algunos no Partes, tienen la obligación de cooperar plenamente con la investigación y enjuiciamiento de crímenes internacionales por parte de la Corte Penal Internacional. Deben asimismo contar en su derecho interno con procedimientos aplicables a todas las formas de cooperación expresamente previstas en la parte IX del Estatuto. La mayoría de los Estados no cumplen con esta última obligación, que es aquella cuyo cumplimiento se puede constatar valiéndose de información pública y que puede ser indiciaria del compromiso estatal de cooperar con la Corte.

${ }^{60}$ Rastan, Rod, cit. (n. 3), p. 171 ss.; Rastan, Rod, cit. (n. 3), pp. 454 y 456.

${ }^{61}$ RASTAN, Rod, cit. (n. 3), p. 167: "For the ICC. The exercise of its powers will, in a similar manner, largely depend on the acceptance of its authority in the first instance by the requested state and, should that fail, by the international community".

${ }^{62}$ Bujosa Vadell, Lorenzo, cit. (n. 42), pp. 218 s. Para un comentario acerca de las particularidades que en material de cooperación presentan cada una de las cuatro situaciones que esta investigando la Corte: STAHN, Carsten - SLUITER, Goeran (editores), The Emerging Practice of the International Criminal Court (Brill, Martinus Nijhoff Publishers, 2009), pp. 171 ss. Sobre (todavía no muy abundantes) resoluciones en materia de cooperación, véase: LAUCCI, Cyril, The Annotated Digest of the International Criminal Court 2007 (Leiden, Martinus Nijhoff Publishers, 2009), II, p. 305 ss.

${ }^{63}$ Véase, por todos: Rastan, Rod, cit. (n. 3), pp. 165 s. 
El cumplimiento de estas obligaciones resulta crucial para la actividad de la Corte, ya que ésta carece por regla generalísima de atribuciones para llevar adelante medidas coercitivas en territorio Estatal sin la cooperación del Estado de que se trate. Con todo, la falta de cumplimiento de estas obligaciones no cuenta en todos los casos con consecuencias jurídicas expresamente previstas. Sólo en ciertos casos, cuando un Estado Parte se niegue a dar curso a una solicitud de cooperación formulada por la Corte, impidiéndole ejercer sus funciones y atribuciones, y esto suceda en contravención con el Estatuto, se prevé un procedimiento a seguir, sin que sea del todo claro qué consecuencia recaerá en definitiva sobre el Estado incumplidor. Esto, que a primera vista puede aparecer como una debilidad del sistema, pierde importancia cuando se piensa en la experiencia de los Tribunales Penales Internacionales ad hoc, que teniendo a su disposición importantes mecanismos de sanción no han sido eficaces en asegurar la cooperación estatal. En definitiva, la amenaza de fieras sanciones en caso de incumplimiento no es el mejor camino para promocionar la ratificación masiva del Estatuto ni para convencer a los Estados eventualmente reticentes a cooperar, de hacerlo efectivamente en un caso dado. Vale más procurar fortalecer la auctoritas de la Corte y educar en cuanto a su mandato y la capital importancia de la cooperación estatal para llevarlo a cabo.

[Recibido el 25 de enero y aceptado el 19 de abril de 2010].

\section{BibLIOGRAFÍA}

Arcos Vargas, Marycruz, La imprescindible cooperación de los Estados con la Corte Penal Internacional, en Carrillo SAlCedo, Juan Antonio (coordinador), La criminalización de la barbarie: La Corte Penal Internacional (Madrid, Consejo General del Poder Judicial, 2000).

Ascencio, Hervé - Decaux, Emmamuel - Pellet, Alain (directores), Droit International Pénal (París, Pedone, 2000).

Bassiouni, M. Cherif, The Legislative History of the International Criminal Court: Introduction. Analysis and Integrated Text (Ardsley, Transnational Publishers, 2005), tres tomos.

Bujosa Vadell, Lorenzo, La cooperación procesal de los Estados con la Corte Penal Internacional (Barcelona, Atelier 2008).

Camargo, Pedro Pablo, Manual de Derecho penal internacional (Bogotá, Editorial Leyer, 2004).

Cárdenas Aravena, Claudia, Die Zulässigkeitsprüfung vor dem Internationales Strafgerichtshof (Berlín, Berliner Wissenschaftsverlag, 2005).

Cárdenas Aravena, Claudia, La Corte Penal Internacional y su relación con las jurisdicciones nacionales: El principio de complementariedad, en Revista de Magister y Doctorado en Derecho, 1 (Universidad de Chile, 2007). 
Cassese, Antonio - Gaeta, Paola - Jones, John, The Rome Statute of the International Criminal Court: A Commentary (Oxford, Oxford University Press, 2002), II.

Cid Muñoz, María Isabel, La Corte Penal Internacional, un largo camino (Madrid, Dykinson, 2008).

CRYER, Robert y otros, An Introduction to International Criminal Law and Procedure (Cambridge, Cambridge University Press, 2007).

ENGSTROM, Viljam, Implied Powers of International Organizations: on the Character of a Legal Doctrine, en Finnish Yearbook of International Law, 24 (2003).

GARTNER, Irene, The Rules of Procedure and Evidence on Co-operation and Enforcement, en FisCher, Horst - Kress, Claus - Lueder, Sascha Rolf (editores), International and National Prosecution of Crimes under International Law, Current Developments (2a. Edición, Berlín, Berliner Wissenschaftsverlag, 2004).

Heilmann, Daniel, Die Effektivität des Internationalen Strafgerichtshofs (Baden-Baden, Nomos, 2006).

Herencia Carrasco, Salvador (coordinador), La Corte Internacionaly los Paises Andinos (3 edición, Lima, Comisión Andina de Juristas, 2007).

Jacobs, Dov, A Samson at the International Criminal Court: The Powers of the Prosecutor at the Pre-Trial Phase, en The Law and Practice of International Courts and Tribunals, 6 (2007).

Kaul, Hans-Peter - Kress, Klaus, Jurisdiction and Cooperation in the Statute of the International Criminal Court: Principles and Compromises, en Yearbook of International Humanitarian Law, 2 (1999).

Kaul, Hans-Peter, The International Criminal Court - Its Relationship to Domestic Jurisdictions, en STAHn, Carsten - Sluiter, Goeran (editores), The Emerging Practice of the International Criminal Court (Leiden, Martinus Nijhoff, 2009).

KlefFner, Jann, Complementarity in the Rome Statute and National Criminal Jurisdictions (Oxford, Oxford University Press, 2008).

Knoops, Geert-Jan Alexander, Surrendering to International Criminal Courts: Contemporary Practice and Procedures (Ardsley, Transnational Publishers, 2002).

Kress, Claus - Prost, Kimberly - Wilkizki, Peter, Part9, en Triffterer, Otto (editor), Commentary on the Rome Statute of the International Criminal Court - Observers' Notes, Article by Article (2a edición, Munich, Beck, 2008).

LaUCCI, Cyril, The Annotated Digest of the International Criminal Court 2007 (Leiden, Martines Nijhoff Publishers, 2009).

Lirola Delgado, Isabel - Martín Martínez, Magdalena, La Corte Penal Internacional, justicia versus impunidad (Barcelona, Ariel, 2001).

MaIKOwsKI, Tatjana, Staatliche Kooperationspflichten gegenüber dem Internationalen Strafgerichtshof (Berlín, Berliner Wissenschaftsverlag, 2002).

MeISSNER, Jörg, Die Zusammenarbeit mit dem Internationalen Strafgerichtshof nach dem Römischen Statut (Munich, Beck, 2003).

Miskowiak, Kristina, Consent, Complementarity and Cooperation (Copenhagen, DJOFPublishing, 2000).

Мосносноко, Phakiso, International Cooperation and Judicial Assistence, en LeE, Roy (editor), The International Criminal Court, the Making of the Rome Statute (The Hague, Kluwer, 1999).

Nsereco, Daniel, Cooperation with the Court on Matters of Arrest and Surrender of Indicted Fugitives: Lessons Form the Ad Hoc Tribunals and National Jurisdictions, 
en Doria, José y otros. (editores), The Legal Regime of the ICC: Essays in Honour of Prof. I. P. Blishchenko (Leiden, Brill, 2009).

Oostervald, Valerie - Perry, Mike - Mcmanus, John, The Cooperation of States with the International Criminal Court, en Fordhan International Law Journal, 25 (marzo de 2001).

Palmisano, Giuseppe, Cooperation by non-States Parties, en LatTanzi, Flavia. The International Criminal Court. Comments on the Draft Statute (Napoli, Editoriale Scientifica, 1998).

Quesada AlCalÁ, Carmen, La Corte Penal Internacional y la soberanía estatal (Valencia, Tirant lo Blanch, 2005).

Rama-Montaldo, Manuel, International Legal Personality an Implied Powers of International Organizations, en British Yearbook of International Law, 44 (1970).

Rastan, Rod, Testing Co-operation: The international Criminal Court and National Authorities, en Leiden Journal of International Law, 21 (2008).

Rastan, Rod, The Responsibility to Enforce - Connecting Justice with Unity, en STAHn, Carsten - Sluiter, Goeran (editores), The Emerging Practice of the International Criminal Court (Leiden, Brill, 2009).

RegGIO, Andrea, Cooperation with the International Criminal Court and National Legal Sytems: An Overview of the Implementing Legislations Enacted so Far, en The Global Community Yearbook of International Law and Jurisprudence, 1 (2003).

SKUBISZEWSKI, Krzysztof, Implied Powers of International Organizations, en DinsteIN, Yoram (editor), International Law at a Time of Perplexity (Dordrecht, Martinus Nijhoff 1989).

Steinberger-Fraunhofer, Theresa, Internationales Strafgerichtshof und Drittstaaten (Berlín, Dunker \& Humblot, 2008).

WeI, Wu, Die Rolle des Anklägers eines internationalen Strafgerichtshofs (Frankfurt am Main, Peter Lang Verlag, 2007).

Zahar, Alexander - Sluiter, Göran, International Criminal Law (Oxford, Oxford University Press, 2008). 